\title{
Immunohistochemically detectable metallothionein expression in malignant pleural mesotheliomas is strongly associated with early failure to platin-based chemotherapy
}

\author{
Fabian D. Mairinger ${ }^{1, *}$, Jan Schmeller ${ }^{1, *}$, Sabrina Borchert $^{1}$, Michael Wessolly $^{1}$,

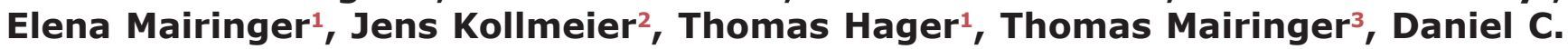 \\ Christoph $^{4,5}$, Robert F.H. Walter ${ }^{1,6}$, Wilfried E.E. Eberhardt ${ }^{4,6}$, Till Plönes ${ }^{7}$, Jeremias \\ Wohlschlaeger ${ }^{1,8}$, Bharat Jasani ${ }^{9}$, Kurt Werner Schmid ${ }^{1}$ and Agnes Bankfalvi ${ }^{1}$ \\ ${ }^{1}$ Institute of Pathology, University Hospital Essen, University of Duisburg-Essen, Essen, Germany \\ ${ }^{2}$ Department of Pneumology, Helios Klinikum Emil von Behring, Berlin, Germany \\ ${ }^{3}$ Department of Pathology, Helios Klinikum Emil von Behring, Berlin, Germany \\ ${ }^{4}$ Department of Medical Oncology, West German Cancer Center, University Hospital Essen, University of Duisburg-Essen, \\ Essen, Germany \\ ${ }^{5}$ Department of Internistic Oncology, Kliniken Essen Mitte, Essen, Germany \\ ${ }^{6}$ Ruhrlandklinik, West German Lung Centre, University Hospital Essen, University of Duisburg-Essen, Essen, Germany \\ ${ }^{7}$ Department of Thoracic Surgery and Thoracical Endoscopy, Ruhrlandklinik, University Hospital Essen, University of Duisburg- \\ Essen, Essen, Germany \\ ${ }^{8}$ Department of Pathology, Diakonissenkrankenhaus Flensburg, Flensburg, Germany \\ ${ }^{9}$ Department of Pathology, Targos Molecular Pathology GmbH, Kassel, Germany \\ *These authors have contributed equally to this work \\ Correspondence to: Fabian D. Mairinger, email: fabian.mairinger@uk-essen.de \\ Keywords: malignant pleural mesothelioma; metallothionein; overall survival; prognostic biomarker; platin-based chemotherapy; \\ Pathology \\ Received: August 18, $2017 \quad$ Accepted: March 11, $2018 \quad$ Published: April 27, 2018 \\ Copyright: Mairinger et al. This is an open-access article distributed under the terms of the Creative Commons Attribution License \\ 3.0 (CC BY 3.0), which permits unrestricted use, distribution, and reproduction in any medium, provided the original author and \\ source are credited.
}

\section{ABSTRACT}

Background: Malignant pleural mesothelioma (MPM) is a biologically highly aggressive tumor arising from the pleura with a dismal prognosis. Cisplatin is the drug of choice for the treatment of MPM, and carboplatin seems to have comparable efficacy. Nevertheless, cisplatin treatment results in a response rate of merely $14 \%$ and a median survival of less than seven months. Due to their role in many cellular processes, methallothioneins (MTs) have been widely studied in various cancers. The known heavy metal detoxifying effect of MT-I and MT-II may be the reason for heavy metal drug resistance of various cancers including MPM.

Methods: 105 patients were retrospectively analyzed immunohistochemically for their MT expression levels. Survival analysis was done by Cox-regression, and statistical significance determined using likelihood ratio, Wald test and Score (logrank) tests.

Results: Cox-regression analyses were done in a linear and logarithmic scale revealing a significant association between expression of MT and shortened overall survival $(O S)$ in a linear $(p=0.0009)$ and logarithmic scale $(p=0.0003)$. Reduced progression free survival (PFS) was also observed for MT expressing tumors (linear: $p=0.0134$, log: $p=0.0152$ ).

Conclusion: Since both, overall survival and progression-free survival are negatively correlated with detectable MT expression in MPM, our results indicate 


\begin{abstract}
a possible resistance to platin-based chemotherapy associated with MT expression upregulation, found exclusively in progressive MPM samples. Initial cell culture studies suggest promoter DNA hypomethylation and expression of miRNA-566 a direct regulator of copper transporter SLC31A1 and a putative regulator of MT1A and MT2A gene expression, to be responsible for the drug resistance.
\end{abstract}

\section{INTRODUCTION}

Malignant pleural mesothelioma (MPM) is a predominantly asbestos-related and biologically highly aggressive tumor associated with a remarkably poor prognosis $[1,2]$. A standardized and optimal management of MPM is lacking, although detailed practical guidelines for the treatment of patients with MPM have been proposed [1-4]. Multimodality therapy consisting of chemotherapy, surgery and/or radiotherapy is centered on surgical resection in early stages. Currently, cisplatin is the drug of choice for the treatment of MPM, and carboplatin seems to have comparable efficacy [1, 3-7]. Combined with antifolates, both drugs are currently considered as the most effective regimen for MPM [7-10]. Nevertheless, cisplatin treatment results in a response rate of merely $14 \%$ and a median survival of less than seven months [8]. Carboplatin resulted in similar response rates ranging from 6 to $16 \%[8,11]$.

Gender, histological subtype and hematological parameters have been identified as important prognostic parameters $[5,6]$. Prognostic biomarkers related to survival of MPM patients and detectable in tumor specimens are however still lacking. Moreover, current guidelines clearly emphasize the need of innovative and novel therapies. For this, further basic research is needed to provide a more detailed insight into the pathogenesis and biology of MPM allowing opportunities for new treatment strategies [1].

Platin-analoga are genotoxic compounds inducing DNA damage [12] which in turn leads to TP53 induced cell cycle arrest and apoptosis [13]. It is however uncertain whether the failure of this mechanism alone is responsible for the impaired therapy response. Several studies have therefore attempted to identify molecular properties shared by MPMs to understand the basis of the poor treatment response [8, 11, 14-18].

Metallothionein (MT) is a family of cytoplasmic, cysteine-rich, low-molecular-mass proteins capable of binding heavy metals through the thiol groups of its cysteine residues [19]. There are four main isoforms expressed in humans (MT-I to MT-IV) with MT-I and MTII representing the most prevalently expressed isoforms. Due to their role in various cellular processes, MTs have been studied in many malignancies [20]. MT has been shown to mediate resistance towards several toxic heavy metals, but compared to cadmium, the effect of MT on them is far less well studied [21]. We hypothesize that a possible mechanism of platinum containing chemotherapy failure may be based on enhanced MT expression by tumor cells.
RESULTS

\section{Clinicopathological data}

Of the 105 patients, 84 were males $(80 \%)$ and 21 females $(20 \%)$. The mean age at date of diagnosis was 65 years (median: 65, range: 34-82). Survival data of 100 patients were available for statistical analysis. 86 of the patients with available clinical data had succumbed to their disease, and 14 patients were still alive at the time of data collection. For five patients, no follow-up data were available. Median overall survival was 19.0 months (mean without censored patients: 23.9 months; $95 \%$ CI: 9.6-30.7 months, min: 1.2 months, max: 91.3 months), median progression-free survival was 7.5 months (mean without censored patients: 12.2 months; $95 \%$ CI: 5.9-12.3 months, min: 1.9 months, max: 64.7 months). 96 of the 105 cancers comprised MPM of the epithelioid subtype (91\%), 5 of the biphasic subtype (5\%), and 4 of the sarcomatoid subtype (4\%). $70 \%$ of the patients initially underwent decortication, $20 \%$ pleurodesis, $5 \%$ pleuropneumectomy and for $5 \%$ patients the surgical therapy could not be assigned due to anonymization properties. The patients received platinum-based therapy (cis- or carboplatin) with varying numbers of chemotherapeutic cycles. With these therapeutic regimens, 42 patients showed stable disease (SD) (40\%), 7 partial response (PR) (7\%), and 54 progressive disease (PD) $(51 \%)$ and for 2 patients the radiological response was not assessed (2\%).

\section{Metallothionein expression in human MPM and associations with clinicopathological factors}

21 tumors (20.0\%) showed MT protein expression with 15 (71.4\%) with Score 1; 5 (23.8\%) with Score 2; and 1 (4.8\%) with Score 3, respectively (Figure 1). Regarding the subcellular localization of MT-expression, fortyeight percent of the MT-positive tumors $(\mathrm{n}=10)$ showed a combined nuclear and cytoplasmic staining reaction, six tumors $(28 \%)$ demonstrated a faint nuclear and 5 tumors (24\%) a week cytoplasmic staining. MT-expression could rarely be detected in epithelioid variants of MPM, more often in biphasic tumors and in a gross of sarcomatoid ones (p-value: 0.0039; Figure 2A).

No significant association was found between MT expression and tumor progression $(\mathrm{p}=0.078)$ or remission $(p=0.089)$ under platin-based chemotherapy. However, it is noteworthy that a positive staining reaction against MT (cut-off $1 \%$ ) was observed only in progressive tumors (n $=21 / 54)$ with none of the remissive or stable $(n=0 / 51)$ showing any staining (Figure 2B/2C). 


\section{Survival analyses}

No association was observed between survival and patients' gender $(\mathrm{p}=0.2643)$, but sarcomatoid and biphasic variants despite the small number of cases included showed significantly shortened patients' overall survival $(p=0.0036)$. With respect to functional scaledifferences in biological systems, Cox-regression analyses were done in a linear and logarithmic scale revealing a significant association between expression of MT and shortened overall survival (OS) in a linear $(\mathrm{p}=0.0009)$ and logarithmic scale $(\mathrm{p}=0.0003$; Figure $3 \mathrm{~A})$. For PFS, again a strongly reduced survival rate could be observed for MT expressing tumors (linear: $\mathrm{p}=0.0134, \log$ : $\mathrm{p}=0.0152$; Figure 3B). Whereas MT-negative MPMs showed a 3 -years-overall-survival rate of approximately $35 \%$, none of the 21 patients with positive metallothionein staining were still alive beyond this time period. Similarly, the metallothionein expressing tumors with the longest stable disease showed progression within 20 months of therapy, whereas $20 \%$ of MT-negative tumors were still stable or in remission at this time point.

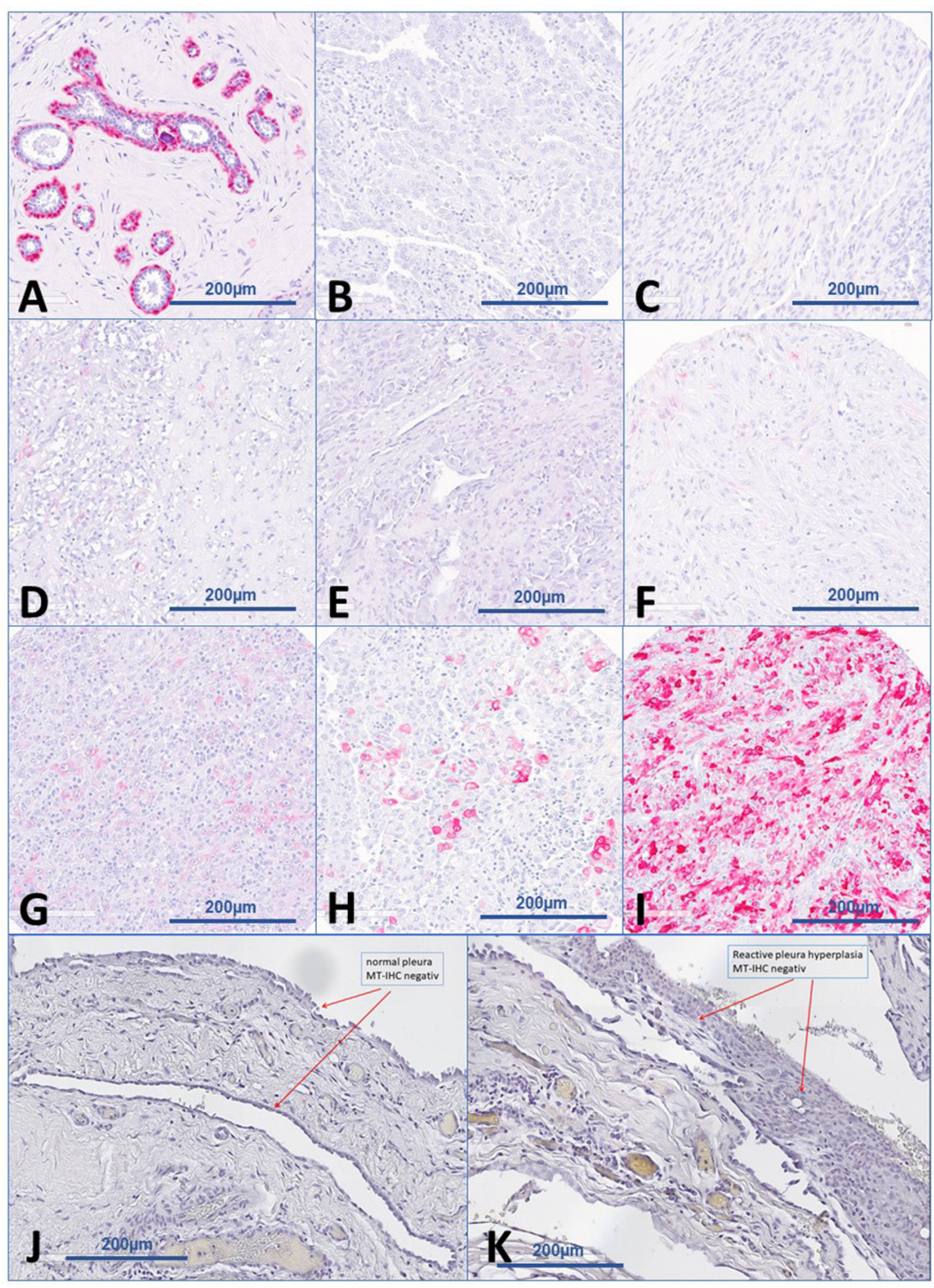

Figure 1: Examples of immunohistochemical staining scores. (A) normal breast with myoepithelial cell as positive control. (B) immunohistochemically negative epitheloid MPM (Score 0). (C) Immunohistochemically negative sarcomatoid MPM (Score 0). (D) Immunohistochemically cytoplasmic positive MPM (Score 1). (E) Immunohistochemically nuclear positive MPM (Score 1). (F) Immunohistochemically cytoplasmic and nuclear positive MPM (Score 1). (G) Immunohistochemically cytoplasmic positive MPM (Score 2). (H) Immunohistochemically cytoplasmic and nuclear positive MPM (Score 2). (I) Immunohistochemically cytoplasmic and nuclear positive MPM (Score 3). (J) Immunohistochemically negative (Score 0) benign pleura. (K) Immunohistochemically negative (Score 0) reactive pleural hyperplasia. 
Considering only tumors of the epitheloid histological subtype, Cox-regression analyses also revealed a significant association between expression of MT and shortened overall survival (OS) in a linear $(p=0.0016)$ and logarithmic scale $(p=0.0011$; Figure $3 C)$.

\section{Immunohistochemical staining of cell lines}

All three analyzed MPM cell lines show detectable MT-immunoexpression levels, while the fibroblast cell line MCR-5 appears negative.

In principle, two different patterns of subcellular spatial distribution of MT protein expression could be observed pretreatment: 1) a weak MT expression prominent in the nucleus (MSTO-211H, Figure 4B) and 2) a strong and mainly cytoplasmic MT expression (NCI-H2452 and NCI-H2052, Figure 4D/4F).

After $24 \mathrm{~h}$ incubation with cisplatin, no significant changes in MT expression levels occurred in any of the cell lines, only MSTO-211H and MRC-5 histologically showed cytoplasmic vacuolization and overall regressive morphology (Figure 5). After 48h, NCI-H2052 and NCI-H2452 showed both an increasing staining intensity as well as an increased number of cells showing positivity for MTs (Table 1).

\section{Cell state analysis}

While cell lines MRC-5 and MSTO-211H showed a strong induction of apoptosis and senescence by treatment
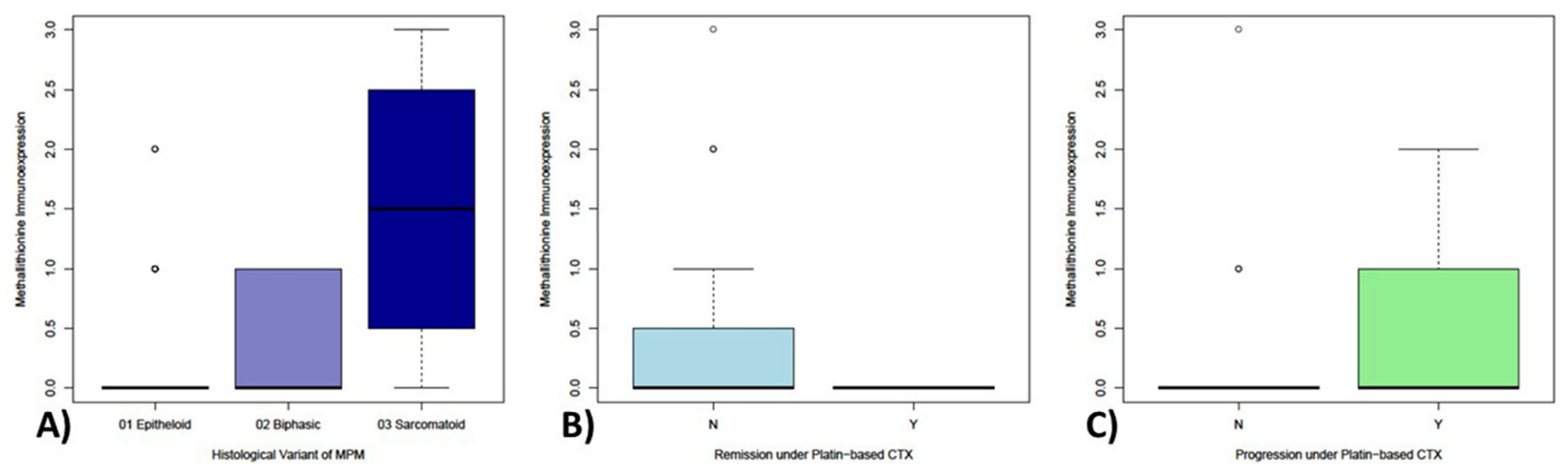

Figure 2: Differential expression of metallothionein in MPM samples with respect to histological and therapy-associated subgroups. Metallothionein expression significantly increases from epitheliod (highlighted in light-blue) over biphasic (highlighted in middle-blue) up to sarcomatoid (highlighted in dark-blue) MPM (2A). Epitheloid tumors show only MT-expression in a very limited population of MPM, whereas biphasic show an increased portion of expressing samples and sarcomatoid show MT-expression in the majority of samples. Strikingly, MT-immunoexpression could only be detected in tumors without remission (2B) and nearly exclusively on progressive tumors (2C) under platin-based chemotherapy.
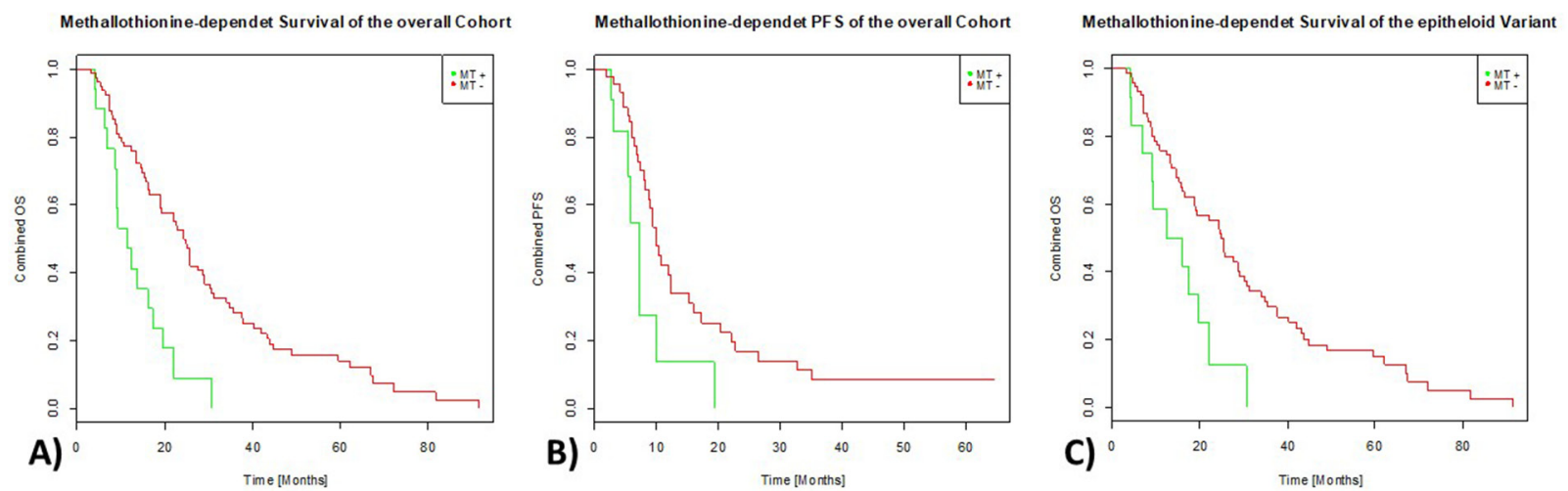

Figure 3: Effect of MT-immunoexpression on survival parameters. MT expressing MPMs (green line) show a significantly shortened OS-rate (3A) as well as PFS rate (3B) compared to MPM samples without measurable expression of MT (red line). The same effect could be observed in epitheloid tumors only (3C). 


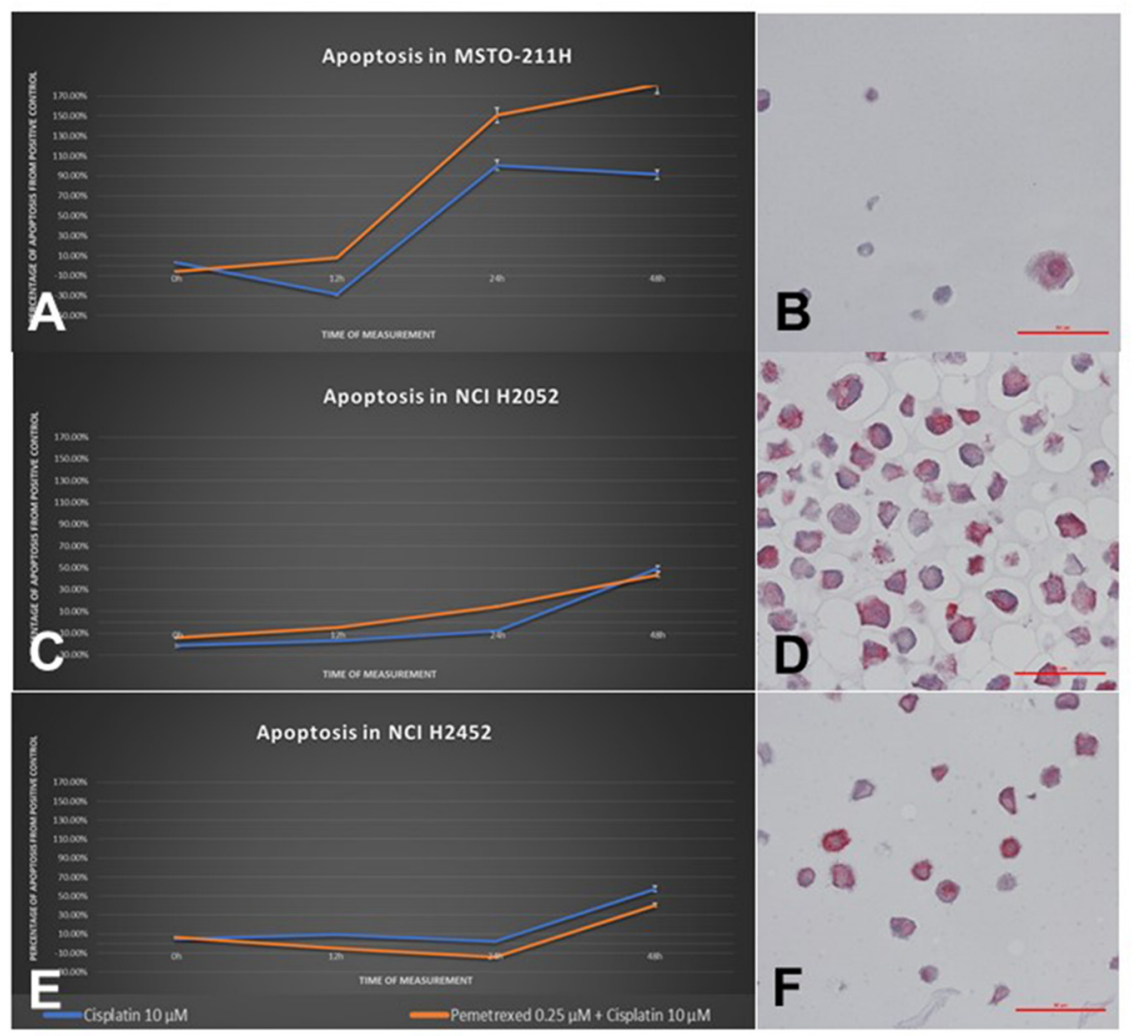

Figure 4: Cellular response of human MPM cell lines to treatment with cisplatin as a single agent and in combination with pemetrexed. The left column (A/C/E) shows CASP3 activity of each cell line in a time-dependent manner, the right column (B/D/F) shows MT-immunostaining pattern of each respective cell line. MSTO-211H cells show a good induction of apoptosis due to cisplatin starting from 12h and a weak MT expression prominent in the nucleus. In contrast, the cell lines NCI-H2052 as well as NCI-H2452 show a significantly delayed and extenuated cellular response, reaching a CASP3-activity maximum of 30-40\% at $48 \mathrm{~h}$. Both cell lines show a strong cytoplasmic protein expression of MT.

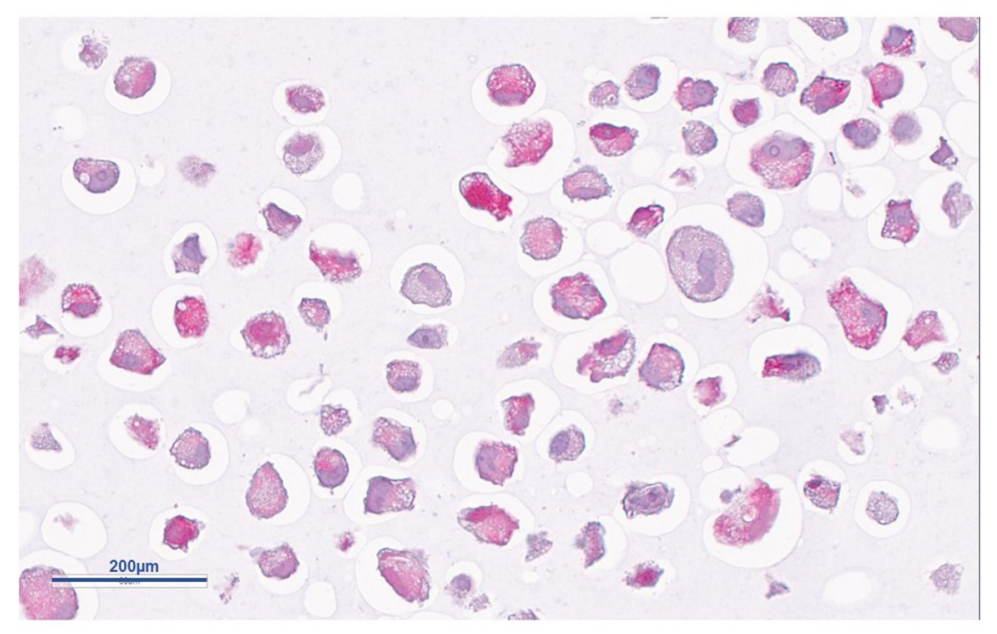

Figure 5: H\&E staining of MSTO211H cells after 24h of incubation with cisplatin. Nearly all cells show numerous regressive transformations like cytoplasmic vacuolization and fuzzy cell shape. 
Table 1: Metallothionein immunoexpression in human MPM cell lines

\begin{tabular}{|c|c|c|c|c|}
\hline & Cell type & Baseline* $^{*}$ & $24 h^{*}$ & $48 h^{*}$ \\
\hline MRC-5 & benign & - & - & No vital cells \\
\hline MSTO-211H & mesothelioma & $(+)$ & $(+)$ & No vital cells \\
\hline NCI-H2452 & mesothelioma & + & + & ++ \\
\hline NCI-H2052 & mesothelioma & ++ & ++ & +++ \\
\hline
\end{tabular}

* Time since incubation with cisplatin.

with cisplatin, NCI-H2052 and NCI-H2452 cells showed a notably lower induction of apoptosis regarding cisplatintreatment (Figure 4A/4C/4E). Also conspicuous was the delayed initial response, shifting from below $12 \mathrm{~h}$ (MRC5 and MSTO-211H) up to past 24h (NCI-H2052 and NCI-H2452).

No induction of necrosis could be observed with either of the used agents, except for the MSTO-211H cells (data not shown). Especially, wells treated with pemetrexed as single agent or in combination showed a necrotic effect.

\section{MT protein expression is associated with miRNA-566}

Interestingly, a significantly altered miRNA expression signature could be identified in the subgroup of MT positive MPM compared to negative tumors. 34

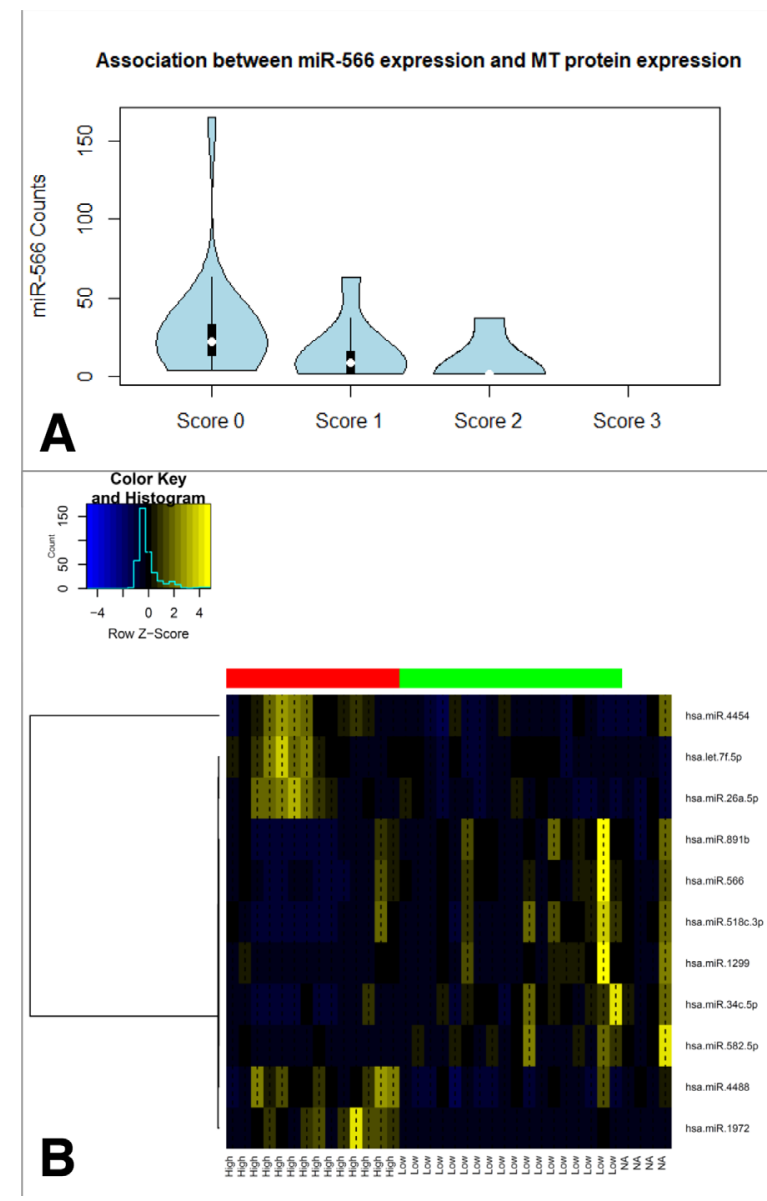

Figure 6: Associations between miRNA expression levels and MT proteinexpression in clinical MPM samples. Overall, five miRNAs show an induction within the group of MT positive tumors and another six ones in MT negative samples (B). Of special interest, as it probably directly regulates MT1A, MT2A as well as SLC31A1, miR566 expression clearly drops in samples showing detectable MT immunoexpression (A). 
Table 2: GO-analysis results

\begin{tabular}{ll}
\hline GO category & p-value \\
\hline cellular response to cisplatin & 0.00004 \\
ion binding & 0.00199 \\
protein methyltransferase activity & 0.00212 \\
cell wall chitin metabolic process & 0.00247 \\
cellular response to radiation & 0.00247 \\
\hline
\end{tabular}

Table 3: Overview of patients characteristics

\begin{tabular}{lc}
\hline Number of patients & $\mathbf{1 0 5}$ \\
\hline Gender & 84 \\
male & 21 \\
female & 0 \\
unknown Gender & \\
Histological subtype & 96 \\
epitheliod & 5 \\
biphasic & 4 \\
sarcomatoid & $65 \mid 65$ \\
Age & $34-82$ \\
Mean | Median age at diagnosis (months) & \\
Range (months) & 86 \\
OS & 14 \\
Deceased & 5 \\
Alive & $19.0 \mid 23.9$ \\
Lost-of-FU & $9.6-30.7$ \\
Median | Mean OS (months) & \\
$95 \%$ CI & $7.5 \mid 12.2$ \\
PFS & $5.9-12.3$ \\
Partial remission (initial) & 72 \\
Stable disease (initial) & 54 \\
Progressive disease (initial) & 2 \\
Unknown response & \\
Median | Mean PFS (months) & \\
$95 \%$ CI & \\
\hline & \\
\hline
\end{tabular}

miRNAs were shown to differ between both group, eleven of those got determined as highly significant ( 5 miRNAs are associated with high and 6 with a low MT-expression, Figure 6B). Of note, only a few of those miRNAs directly regulate metallothionein genes.
Strikingly, miR-566, probably regulating MT1A (binding probability: $\mathrm{p}=0.0203$ ) as well as MT2A (binding probability: $p=0.0203$ ), is involved in the transport of platinum derived agents into the cell via direct regulation of the copper transporter SLC31A1. Moreover, increased 
miR-566 expression was significantly associated with higher MT protein levels (Figure 6A)

A GO-analysis revealed "cellular response to cisplatin" as well as "cellular response to radiation" both within the Top5 of influenced cellular processes (Table 2)

\section{TCGA data sets and associations to promotor methylation levels}

mRNA expression as well as methylation levels of none of the MT-family members showed a significant association to patients' overall survival rate, except metallothionein 1D pseudogene (MT1DP, mRNA xp: $p=0.0035$, methylation: $p=0.0270)$. Also, copy-number alterations (CNA) of none of the genes seem to be a relevant factor for overall survival time, although both deletions and especially gains could be detected (Supplementary Figure 2). Furthermore, no mutations in MT genes have been observed in any of the samples.

Interestingly, gene expression of nearly all MT family members appeared to be strongly dependent on DNA promotor hypomethylation, as only tumors with promotor methylation levels below approx.15\% show gene expression levels at all (Supplementary Figure 2). CNA seem not to impact this. Furthermore, the different MT's seem to be co-regulated within each sample (Supplementary Figure 1).

\section{DISCUSSION}

Due to their role in various cellular processes, MTs have been widely studied in various cancers [20]. MTs are known for their regulatory role during oxidative stress, their function involves ROS scavenging and ROS inhibition [22]. Furthermore, a depletion of NO-mediated cytotoxicity in MT overexpressing transgenic mice has been observed [23]. Metallothionein (MT) was reported to be a potential negative regulator of apoptosis, and various reports have suggested that it may play roles in carcinogenesis and drug resistance [24].

As described above, cisplatin shows cytotoxic effect depending on the concentration of heavy metal compounds. The heavy metal detoxifying effect from MT-I and MT-II may be the reason for the inactivation of alkylating drugs like platin-containing compounds (e.g. cis-platin or carbo-platin) $[25,26]$.

MTs are widely differently expressed in various tumor entities. While there is an overexpression in breast, uterine and skin carcinomas, they are downregulated in prostate carcinoma/adenoma, small cell lung carcinomas and hepatic carcinomas [27]. Whereas recent studies have showed a tumor suppressory role of some MT isoforms in papillary thyroid carcinoma, and cancers of the large intestine and melanomas [28-30], MTs have been shown to promote the progression of adenocarcinoma of the breast and lung [31-33]. Furthermore, the role of MTs in invasiveness, migration and sensitivity to anticancer agents has been widely studied [34-38].

A previous study showed a positive immunoreactivity against metallothionein in more than a half of diffuse MPM, and an increased MT protein expression level in patients with environmental asbestos exposure [39]. Additionally, in a portion of MPM samples, the MT locus was found to be silenced by DNA hypermethylation [40], resulting in a lack of MT expression and activity.

In our present study, immunohistochemical expression of MT was detected in approximately $20 \%$ of MPM samples, all in tumors with progressive clinical course despite chemotherapy. Therefore, our results indicate a possible resistance to platin-based chemotherapy in MPMs which exhibit enhanced MTexpression. Both, overall survival and progression-free survival are negatively correlated to detectable MT expression in MPM.

Similar discoveries have been already observed in ovarian, bladder, esophagus, liver and tongue cancer [41-43]. Furthermore, it is striking that MT expression could only be detected in progressive MPM but never in cancer showing remission under chemotherapy. However, in contrast to our data, no significant associations between MT expression in MPM and survival of the patients were found in another study [39].

Interestingly, the results rendered out of the TCGA data-base do not fully reflect our immunohistochemical findings, as mRNA expression levels of none of the MT genes was associated with overall survival. This could be explained in main by two reasons:

1. a dis-concordance between mRNA and protein expression levels have been described in many tissues like circulating monocytes [44], lung adenocarcinoma [45] or prostate cancer [46]; and

2. the survey of OS data is strongly dependent on the data collection and can differ with different parameters applied. Unfortunately, no data about response to therapy or progression-free survival are available within the TCGA data set.

Additional evidence for our hypothesis of MTmediated platin-resistance in MPM could be generated by our in vitro inhibitory experiments. The direct association between strong cytoplasmic staining, clearly reduced apoptosis as well as cellular senescence rate completes the picture of clearly shortened OS and PFS and early therapy failure under platin treatment. Of note, contrary to the patient samples, all investigated cell lines showed at least a weak nuclear MT staining. We explain this by the difference in formalin-fixation between tissue and cell blocks, leading to a shift in the detection limit and staining background.

Findings reveal that subcellular localization of MT is important for its predictive and prognostic value $[42,43]$. In ovarian cancer, nuclear MT-I expression was 
shown to be induced during platin-based treatment which led to cancer progression, relapse and increased mortality, whereas no relationship was found between cytoplasmic expression and patients' outcome, possibly by inhibiting the binding of cisplatin to DNA. In our study on mesothelioma biopsies obtained before treatment, the majority of strong and medium MT-expressing tumors showed a mixed cytoplasmic and nuclear staining. Pure and faint nuclear or cytoplasmic reactions were found in scattered tumor cells within the group of low-MT-expressers.

In vivo experiments show an additional resistance to a broad range of anticancer drugs as bleomycin, melphalan, ara-c, cytarabine, etoposide, doxorubicin methotrexate as well as radiotherapy [20, 27, 38, 47-49]. However, this association is discussed controversially, making MT expression to be a non-reliable marker for prognosis [43]. Eid et al. [50], Meijer et al. [51], and Endo et al. [52] predicted a better response to cisplatin.

Resistance against alkylating drugs is one of the main causes of therapeutic failure in highly aggressive human carcinomas. Two main mechanisms of the possible role of MTs are widely discussed in the literature. Firstly, MTs are capable to bind platin-based chemotherapeutic agents as well as their metabolites directly, thereby preventing them from inducing DNA damage [20, 53-55]. Especially the mechanism of binding, inactivation and sequestering of platin has been clarified. The structural studies revealed that MTs bind seven $\mathrm{Zn}$ (II) or $\mathrm{Cd}(\mathrm{II})$ through cysteine thiolates forming two metal-thiolate clusters in the $\beta$-domain as well as the $\alpha$-domain of the protein $[56,57]$. As the affinity of $\mathrm{Pt}(\mathrm{II})$ for cysteine thiolates exceeds that of $\mathrm{Zn}$ (II) for $10^{7}$ fold, $\mathrm{Zn}$ (II) is substituted by $\mathrm{Pt}(\mathrm{II})[57,58]$. However, recently it became evident that the extent, to which MT sequesters platinum drugs, depends not only on the type of cancer, but also on the interaction of MT with the ligand sphere of the platinum center [59].

Secondly, MTs might act as a negative regulator of the effect of the chemotherapy by sequestering zinc ions $[60,61]$, thereby regulating proteins based on zinc ions as cofactor like p53. We also compared MT expression presented within this study with results on p53 and mdm2 from previous investigation from our group [16, 18, $62-$ 64]. However, we could not define significant associations between the two pathways.

The anti-MT antibody (clone E9) we used is able to detect both MT1 and MT2 isoforms [71], of which MT2 is inducible by heavy metals and capable of binding them. Our results support the hypothesis that in MPM it is rather the heavy-metal-binding activity of MT2, which might be causally related to the resistance to platin-based chemotherapy.

Notwithstanding this, p53 is an essential regulator for apoptosis in case of DNA damage repair and recognition [60] and plays an important role in tumorigenesis and response to alkylating chemotherapeutics [16, 18, 62-64].
Previously, possible correlations to clinic-pathological data with the tumor suppressors p53 and MTs were analyzed in MPM samples but revealed no statistical association as well as no correlation to each other [39]. Nevertheless, in previous experiments, we found a significantly poorer survival in patients with MDM2-expressing MPMs of the epithelioid and biphasic subtypes [62-64]. This might be caused by MDM2-mediated inactivation of functional p53 protein in the setting of TP53 wild-type. Taken together both mechanisms, MDM2 and MT expression might provide an explanation for the way therapy resistance in MPMs is acquired.

As one possible translational strategy based on these results, a supplementation of zinc may overcome the issue of MT-driven platin-resistance by saturation of all free $\mathrm{Pt}(\mathrm{II})$ binding sites with high concentrations of $\mathrm{Zn}(\mathrm{II})$. Kocdor et al. could show in vitro, that the supplementation of $50 \mu \mathrm{M}$ zinc into the cell culture media reduces the IC50 value of docetaxel from $20.4 \mu \mathrm{M}$ to 8.1 , the supplementation of $100 \mu \mathrm{M}$ zinc even down to $6.6 \mu \mathrm{M}$ [65]. Contrarily, Alscher et al. could show an induction of MT gene- and protein expression levels in mesothelial cells via zinc [66]. This will reduce the sensitivity to chemotherapy, and it remains to be proven if there is a protective effect of this to either benign pleural tissue or pleural mesothelioma or not.

\section{MATERIALS AND METHODS}

\section{Demographic data}

Formalin-fixed paraffin-embedded (FFPE) tumor specimens from 105 patients suffering from MPM were screened. Tumor classification was based on the respective WHO classification of tumors (2004) [67], and the TNMstaging on the UICC classification [68]. Both were confirmed by two experienced pathologists (JW, TM). The study included only patients with MPM, treated at the West German Cancer Centre or the West German Lung Centre (Essen) between 2006 and 2009 and the Helios Klinikum Emil von Behring (Berlin) between 2002 and 2009. Inclusion criteria were the availability of both sufficient tumor material and a complete set of data related follow-up and treatment.

Furthermore, gene expression data (RNA Seq) of 87 malignant pleural mesothelioma patients were retrieved from the The Cancer Genome Atlas (TCGA) database (courtesy of National Cancer Institute, National Human Genome Research institute, Bethesda, MD, US).

\section{Clinicopathological data}

Most of the tumors showed epithelioid histology, and only a few cases of biphasic $(n=5)$ and sarcomatoid $(n=$ 4) MPM were available for the study. All specimens were collected prior to systemic treatment. Study surveillance 
was terminated on August 31, 2014. Patients' clinicpathological and clinical data are summarized in Table 3.

Response data were evaluated centralized using the modified Response Evaluation Criteria in Solid Tumors (modRECIST) for assessment of radiological response in MPM [69]. As described elsewhere, for a better stratification, remission was defined by complete response (CR) and partial response (PR) versus stable disease (SD) and progressive disease (PD) [70]. Likewise, progression was defined by CR and PR and SD versus PD [70].

The study was conducted retrospectively and was approved by the Ethics Committee of the Medical Faculty of the University Duisburg-Essen (identifier: 14-5775$\mathrm{BO})$. The investigation conforms to the principles outlined in the declaration of Helsinki.

\section{Cell line experiments}

For in vitro experiments, the cell lines MRC5, MSTO-211H, NCI-H2052 and NCI-H2452 were used. Human MPM cell lines were obtained from the American Type Culture Collection in 2012-08 (Manassas, VA, USA). The cell lines were authenticated and tested for contaminations by using a commercial service (Multiplexion, Heidelberg, Germany) and were last retested directly after the experiments were finished.

Based on reviewing the literature, concentrations for the cytostatic drugs were estimated [71-75].

\section{Maintenance of eukaryotic cells}

Cultivation of cells was done at standard incubator conditions (humidified atmosphere, $5 \% \mathrm{CO} 2,37^{\circ} \mathrm{C}$ ). Cells were maintained in T-75 or T-175 cell culture flasks (Greiner Bio-One, Kremsmünster, Austria) using Roswell Park Memorial Institute (RPMI) - 1640 medium plus $10 \%$ fetal calf serum (FCS) and $1 \%$ Penicillin and Streptomycin $(\mathrm{P} / \mathrm{S}$, Thermo Fisher Scientific, Massachusetts, USA) for tumor cell lines. For MRC-5 cells, minimal essential medium (MEM) plus 10\% FCS and $1 \% \mathrm{P} / \mathrm{S}$ was used. Cells were grown until $95-100 \%$ confluency. Subsequently, after washing twice with $5 \mathrm{ml}$ Dulbecco's Phosphate Buffered Saline (DPBS, Thermo Fisher Scientific) cells were trypsinized with $2 \mathrm{ml}$ of $0.05 \%$ Trypsin-EDTA (Thermo Fisher Scientific) for 5-10 $\mathrm{min}$ at $37^{\circ} \mathrm{C}$. Trypsination was inactivated by resuspending the cells in $8 \mathrm{ml}$ medium for passaging or cell counting. For cell counting, $10 \mu \mathrm{l}$ of cell suspension was mixed with $10 \mu \mathrm{l}$ of trypan blue (Thermo Fisher Scientific) and $10 \mu \mathrm{l}$ of the mix were transferred to the hemocytometer (Brand, Wertheim, Germany).

\section{Treatment of MPM cell lines with cytostatic agents cisplatin and pemetrexed}

The cell lines were analyzed for apoptosis, senescence and necrosis during treatment with pemetrexed and/or cisplatin [76]. These agents was supplied by Selleckchem (Cisplatin: S1166, Pemetrexed: S1135, Houston, USA). Cisplatin was solubilized by Dimethyl sulfoxide (DMSO, Sigma-Aldrich, Missouri, USA) and pemetrexed was solubilized by $\mathrm{dH} 2 \mathrm{O}$.

For the treatment of cells, 5,000 cells $(50 \mu \mathrm{l})$ were seeded into microplates 96/U (Eppendorf, Hamburg, Germany) that are suitable for luminescence detection. The cells could attach overnight at $37^{\circ} \mathrm{C}$ and $5 \% \mathrm{CO} 2$. At the next day, $50 \mu \mathrm{l}$ of fresh medium either containing one of the treatment agents or without additive was applied to each well. The concentrations of the agents were 0.25 $\mu \mathrm{M}$ for pemetrexed and $10 \mu \mathrm{M}$ for cisplatin. Cisplatin was combined with pemetrexed, representing the approved chemotherapeutics for MPM.

\section{Cell state analysis}

Senescence of the cells was analyzed by a luminescent-based activity assay of living cells. The assay was performed using the CellTiter-Glo ${ }^{\circledR}$ Luminescent Cell Viability Assay kit (G7571, Promega). The CellTiter-Glo ${ }^{\circledR}$ reagent was prepared according to the protocol provided by the manufacturer. Digitonin $(30 \mu \mathrm{g} / \mathrm{ml}$, supplied by the kit) served as positive control to measure a decrease of cellular viability of $100 \% .10 \mu \mathrm{l}$ of digitonin was given to the cells $15 \mathrm{~min}$ before cell lysis. Cell lysis was induced by applying $100 \mu \mathrm{l}$ of CellTiter-Glo ${ }^{\circledR}$ reagent to each well and incubated for $10 \mathrm{~min}$ of at room temperature.

The necrosis of cells was analyzed using the CytoTox-Glo ${ }^{\circledR}$ Assay kit (G9191, Promega). 5,000 cells per reaction were used. $100 \mu \mathrm{l}$ of required cells/well were placed in a white 96-well plate. The AAF-Glo ${ }^{\circledR}$ reagent was prepared according to the protocol provided by the manufacturer. Ionomycin (S1160, Selleckchem) was used as positive control. Two hours before measurement, 50 $\mu \mathrm{l}$ of Ionomycin $(100 \mu \mathrm{M})$, was added to the cells. After adding $50 \mu \mathrm{l}$ of the AAF-Glo ${ }^{\circledR}$ reagent to each well, cells were incubated for $15 \mathrm{~min}$ at room temperature, protected from light.

The apoptotic potential of the cells was analyzed using the Caspase-Glo ${ }^{\circledR}$ 3/7 Assay (G8093, Promega). 5,000 cells per reaction were used. $100 \mu$ of required cells/well were placed into a white 96 -well plate. The Caspase-Glo ${ }^{\circledR}$ reagent was prepared according to the protocol provided by the manufacturer. Staurosporine (10 $\mu \mathrm{M}, \mathrm{S} 1421$, Selleckchem) served as positive control and was given to the cells $4 \mathrm{~h}$ before measurement. After adding $100 \mu \mathrm{l}$ of Caspase-Glo ${ }^{\circledR}$ reagent to each well, cells were incubated for $30 \mathrm{~min}$ at room temperature.

All reactions were measured using a luminometer (Glo Max Multi + Detection System; Promega).

\section{Immunohistochemistry}

Formalin-fixed tissues were embedded in paraffin and processed into $4 \mu \mathrm{m}$ thick slides for histomorphological 
diagnosis (H\&E sections) and immunohistochemistry (IHC). For systematic immunohistochemical investigations, tissue microarrays (TMA) were constructed from paraffin blocks. Three cores with a diameter of 0.6 $\mathrm{mm}$ were taken from different areas of each tumor to take possible tumor heterogeneity into account. When feasible, a core containing only normal lung tissue and unaffected pleura was taken from every specimen for negative control purposes. Immunohistochemistry was performed according to standard protocols using an automated staining device (Ventana Discovery XT, Munich, Germany). After validation on reference tissues (myoepithelial cells of normal breast tissue) and normal pleura samples as a negative control, the immunohistochemical investigations were performed with a monoclonal primary antibody (clone E9) (Dako/Agilent, Santa Clara, CA, US) directed against at an epitope shared by MT-1and MT-2 [77]. Pre-treatment for antigen retrieval was performed by heating in citrate buffer (Ultra Cell Conditioning Solution II, Ventana Medical Systems, Basel, $\mathrm{CH}$ ) at $\mathrm{pH} 6,90^{\circ} \mathrm{C}$ for 30 minutes.

Immunohistochemical MT protein expression was evaluated by a senior pathologist and a trained scientist using a consultation light microscope (Nikon Eclipse 80i, Nikon Ltd. Dusseldorf, Germany). A semi-quantitative four-tier IHC scoring system was used based on the percentage of tumor cells with a positive nuclear and/or cytoplasmic immunoreaction with the antibody directed against metallothionein irrespective of staining intensity (Score 0: no immunohistochemical signal; Score 1 (weak expression): $1-5 \%$ MT-positive tumor cells; Score 2 (moderate expression): 6-50\% MT-positive tumor cells; Score 3 (strong expression): $>50 \%$ MT-positive tumor cells) $[77,78]$.

\section{RNA extraction and RNA integrity assessment}

According to the manufacturer's recommendations, three to five paraffin sections with a thickness of $4 \mu \mathrm{m}$ per sample were deparaffinized with xylene prior to total RNA extraction including small RNAs using the miRNeasy FFPE kit (Qiagen, Hilden, Germany). RNA concentration was measured using a Qubit 2.0 fluorometer (Life Technologies) appertaining the RNA broad-range assay. RNA integrity was assessed using a Fragment Analyzer (Advanced Analytical Inc., Ames, IA, USA) appertaining DNF-489 standard sensitivity RNA analysis kit.

\section{NanoString miRNA codeset design and expression quantification}

The commercially available nCounter miRNA Expression Assay v2.1 (NanoString Technologies, Seattle, WA, USA) containing probes and miRTags for the 800 most important known miRNAs described in the context of cancerogenic events was chosen for miRNA Expression analysis. Five potential reference genes (ACTB, B2M, GAPDH, RPL19, RPLP0) were also included in the CodeSet for biological normalization purposes. Probe sets and miRTags for each target in the CodeSet were designed and synthesized at NanoString Technologies (Seattle, WA, USA). $100 \mathrm{ng}$ total RNA were analyzed for each sample (in a final volume of $3 \mu \mathrm{l}$ ). The sample preparation in the nCounter Prep Station (NanoString) was carried out by using the high-sensitivity protocol ( $3 \mathrm{~h}$ preparation). The cartridges were measured at 555 fields of view in the nCounter Digital Analyzer (NanoString).

\section{NanoString data processing and statistical analysis}

Both the statistical and graphical analyses were performed with the $\mathrm{R}$ statistical programming environment (v3.4.2).

NanoString data processing was done using the NanoStringNorm [79] and the NAPPA package, respectively. Considering the counts obtained for positive control probe sets raw NanoString counts for each gene were subjected to a technical factorial normalization, carried out by subtracting the mean counts plus two-times standard deviation from the CodeSet inherent negative controls. Afterwards, a biological normalization using the geometric mean of the 100 top expressed miRNAs was performed. Additionally, all counts with $\mathrm{p}>0.05$ after one-sided t-test versus negative controls plus $2 \mathrm{x}$ standard deviations were interpreted as not expressed to overcome basal noise.

Before starting the analysis, the Shapiro-Wilks-test was applied to test for normal distribution of each data set. Based on the results, either a parametric or non-parametric test was applied. The exact Wilcoxon Mann-Whitney Rank Sum test was used to test associations between the mean protein expression obtained from three cores and dichotomous variables (gender).

Overall survival was calculated by producing single-factorial and combined Kaplan-Meier curves. Survival analysis was done by Cox-regression (COXPHmodel), and statistical significance was determined using likelihood ratio test, Wald test and Score (logrank) test. Kaplan-Meier curves with a confidence interval of $95 \%$ $(95 \% \mathrm{CI})$ were calculated based on existing survival data and combined survival curves were performed.

The level of statistical significance was defined as $\mathrm{p}<0.05$.

\section{CONCLUSION}

Our results show that immunohistochemical MT expression is significantly correlated with poor overall and progression-free survival in MPMs under platin-based chemotherapy, thereby suggesting its possible role as a predictor of resistance to platin-based chemotherapy. 


\section{CONFLICTS OF INTEREST}

The authors declare no conflicts of interest.

\section{REFERENCES}

1. Goudar RK. Review of pemetrexed in combination with cisplatin for the treatment of malignant pleural mesothelioma. Ther Clin Risk Manag. 2008; 4:205-11.

2. Liu Z, Klominek J. Regulation of matrix metalloprotease activity in malignant mesothelioma cell lines by growth factors. Thorax. 2003; 58:198-203.

3. Ramalingam SS, Belani CP. Recent advances in the treatment of malignant pleural mesothelioma. J Thorac Oncol. 2008; 3:1056-64.

4. Vorobiof DA, Mafafo K. Malignant pleural mesothelioma: medical treatment update. Clin Lung Cancer. 2009; 10:112-7.

5. Ceresoli GL, Castagneto B, Zucali PA, Favaretto A, Mencoboni M, Grossi F, Cortinovis D, Del Conte G, Ceribelli A, Bearz A, Salamina S, De Vincenzo F, Cappuzzo F, et al. Pemetrexed plus carboplatin in elderly patients with malignant pleural mesothelioma: combined analysis of two phase II trials. Br J Cancer. 2008; 99:51-6.

6. Ceresoli GL, Zucali PA, Favaretto AG, Grossi F, Bidoli P, Del Conte G, Ceribelli A, Bearz A, Morenghi E, Cavina R, Marangolo M, Parra HJ, Santoro A. Phase II study of pemetrexed plus carboplatin in malignant pleural mesothelioma. J Clin Oncol. 2006; 24:1443-8.

7. Kindler HL. Systemic treatments for mesothelioma: standard and novel. Curr Treat Options Oncol. 2008; 9:171-9.

8. Tomek S, Manegold C. Chemotherapy for malignant pleural mesothelioma: past results and recent developments. Lung Cancer. 2004; 45:S103-19.

9. Mairinger F, Vollbrecht C, Halbwedl I, Hatz M, Stacher E, Gully C, Quehenberger F, Stephan-Falkenau S, Kollmeier J, Roth A, Mairinger T, Popper H. Reduced folate carrier and folylpolyglutamate synthetase, but not thymidylate synthase predict survival in pemetrexed-treated patients suffering from malignant pleural mesothelioma. J Thorac Oncol. 2013; 8:644-53.

10. Mairinger F, Vollbrecht C, Mairinger T, Popper H. The issue of studies evaluating biomarkers which predict outcome after pemetrexed-based chemotherapy in malignant pleural mesothelioma. J Thorac Oncol. 2013; 8:e80-2.

11. Tomek S, Emri S, Krejcy K, Manegold C. Chemotherapy for malignant pleural mesothelioma: past results and recent developments. Br J Cancer. 2003; 88:167-74.

12. Jung Y, Lippard SJ. Direct cellular responses to platinuminduced DNA damage. Chem Rev. 2007; 107:1387-407.

13. Koch M, Krieger ML, Stolting D, Brenner N, Beier M, Jaehde U, Wiese M, Royer HD, Bendas G. Overcoming chemotherapy resistance of ovarian cancer cells by liposomal cisplatin: molecular mechanisms unveiled by gene expression profiling. Biochem Pharmacol. 2013; 85:1077-90.

14. Kamal NS, Soria JC, Mendiboure J, Planchard D, Olaussen KA, Rousseau V, Popper H, Pirker R, Bertrand P, Dunant A, Le Chevalier T, Filipits M, Fouret P; International Adjuvant Lung Trial-Bio investigators. MutS homologue 2 and the long-term benefit of adjuvant chemotherapy in lung cancer. Clin Cancer Res. 2010; 16:1206-15.

15. Kelly RJ, Sharon E, Hassan R. Chemotherapy and targeted therapies for unresectable malignant mesothelioma. Lung Cancer. 2011; 73:256-63.

16. Walter RF, Vollbrecht C, Werner R, Mairinger T, Schmeller J, Flom E, Wohlschlaeger J, Barbetakis N, Paliouras D, Chatzinikolaou F, Adamidis V, Tsakiridis K, Zarogoulidis P, et al. Screening of pleural mesotheliomas for DNA-damage repair players by digital gene expression analysis can enhance clinical management of patients receiving platinbased chemotherapy. J Cancer. 2016; 7:1915-25.

17. Ting S, Mairinger FD, Hager T, Welter S, Eberhardt WE, Wohlschlaeger J, Schmid KW, Christoph DC. ERCC1, MLH1, MSH2, MSH6, and betaIII-tubulin: resistance proteins associated with response and outcome to platinumbased chemotherapy in malignant pleural mesothelioma. Clin Lung Cancer. 2013; 14:558-67 e3.

18. Mairinger FD, Werner R, Flom E, Schmeller J, Borchert S, Wessolly M, Wohlschlaeger J, Hager T, Mairinger T, Kollmeier J, Christoph DC, Schmid KW, Walter RF. miRNA regulation is important for DNA damage repair and recognition in malignant pleural mesothelioma. Virchows Arch. 2017; 470:627-37.

19. Schmitz KJ, Lang $H$, Kaiser G, Wohlschlaeger J, Sotiropoulos GC, Baba HA, Jasani B, Schmid KW. Metallothionein overexpression and its prognostic relevance in intrahepatic cholangiocarcinoma and extrahepatic hilar cholangiocarcinoma (Klatskin tumors). Hum Pathol. 2009; 40:1706-14.

20. Dziegiel P. Expression of metallothioneins in tumor cells. Pol J Pathol. 2004; 55:3-12.

21. Schuhmacher-Wolz U, Dieter HH, Klein D, Schneider $\mathrm{K}$. Oral exposure to inorganic arsenic: evaluation of its carcinogenic and non-carcinogenic effects. Crit Rev Toxicol. 2009; 39:271-98.

22. Andrews GK. Regulation of metallothionein gene expression by oxidative stress and metal ions. Biochem Pharmacol. 2000; 59:95-104.

23. Schwarz MA, Lazo JS, Yalowich JC, Allen WP, Whitmore M, Bergonia HA, Tzeng E, Billiar TR, Robbins PD, Lancaster JR Jr. Metallothionein protects against the cytotoxic and DNA-damaging effects of nitric oxide. Proc Natl Acad Sci U S A. 1995; 92:4452-6.

24. Takahashi S. Molecular functions of metallothionein and its role in hematological malignancies. J Hematol Oncol. 2012; 5:41. 
25. Andrews PA, Murphy MP, Howell SB. Metallothioneinmediated cisplatin resistance in human ovarian carcinoma cells. Cancer Chemother Pharmacol. 1987; 19:149-54.

26. Choi CH, Cha YJ, An CS, Kim KJ, Kim KC, Moon SP, Lee ZH, Min YD. Molecular mechanisms of heptaplatin effective against cisplatin-resistant cancer cell lines: less involvement of metallothionein. Cancer Cell Int. 2004; 4:6.

27. Pedersen MØ, Larsen A, Stoltenberg M, Penkowa M. The role of metallothionein in oncogenesis and cancer prognosis. Prog Histochem Cytochem. 2009; 44:29-64.

28. Ferrario C, Lavagni P, Gariboldi M, Miranda C, Losa M, Cleris L, Formelli F, Pilotti S, Pierotti MA, Greco A. Metallothionein $1 \mathrm{G}$ acts as an oncosupressor in papillary thyroid carcinoma. Lab Invest. 2008; 88:474-81.

29. Arriaga JM, Bravo IA, Bruno L, Morales Bayo S, Hannois A, Sanchez Loria F, Pairola F, Huertas E, Roberti MP, Rocca YS, Aris M, Barrio MM, Baffa Trasci S, et al. Combined metallothioneins and p53 proteins expression as a prognostic marker in patients with Dukes stage B and C colorectal cancer. Hum Pathol. 2012; 43:1695-703.

30. Faller WJ, Rafferty M, Hegarty S, Gremel G, Ryan D, Fraga MF, Esteller M, Dervan PA, Gallagher WM. Metallothionein 1E is methylated in malignant melanoma and increases sensitivity to cisplatin-induced apoptosis. Melanoma Res. 2010; 20:392-400.

31. Jin R, Chow VT, Tan PH, Dheen ST, Duan W, Bay BH. Metallothionein 2A expression is associated with cell proliferation in breast cancer. Carcinogenesis. 2002; 23:81-6.

32. Lai Y, Lim D, Tan PH, Leung TK, Yip GW, Bay BH. Silencing the metallothionein-2A gene induces entosis in adherent MCF-7 breast cancer cells. Anat Rec (Hoboken). 2010; 293:1685-91.

33. Werynska B, Pula B, Muszczynska-Bernhard B, Gomulkiewicz A, Piotrowska A, Prus R, PodhorskaOkolow M, Jankowska R, Dziegiel P. Metallothionein 1F and 2A overexpression predicts poor outcome of non-small cell lung cancer patients. Exp Mol Pathol. 2013; 94:301-8.

34. Jin R, Bay BH, Chow VT, Tan PH. Metallothionein 1F mRNA expression correlates with histological grade in breast carcinoma. Breast Cancer Res Treat. 2001; 66:265-72.

35. Kim HG, Kim JY, Han EH, Hwang YP, Choi JH, Park BH, Jeong HG. Metallothionein-2A overexpression increases the expression of matrix metalloproteinase- 9 and invasion of breast cancer cells. FEBS Lett. 2011; 585:421-8.

36. Ryu HH, Jung S, Jung TY, Moon KS, Kim IY, Jeong YI, Jin SG, Pei J, Wen M, Jang WY. Role of metallothionein 1E in the migration and invasion of human glioma cell lines. Int J Oncol. 2012; 41:1305-13.

37. Kondo Y, Kuo SM, Watkins SC, Lazo JS. Metallothionein localization and cisplatin resistance in human hormoneindependent prostatic tumor cell lines. Cancer Res. 1995; 55:474-7.
38. Kondo Y, Woo ES, Michalska AE, Choo KH, Lazo JS. Metallothionein null cells have increased sensitivity to anticancer drugs. Cancer Res. 1995; 55:2021-3.

39. Isik R, Metintas M, Gibbs AR, Metintas S, Jasani B, Oner U, Harmanci E, Demircan S, Işiksoy S. p53, p21 and metallothionein immunoreactivities in patients with malignant pleural mesothelioma: correlations with the epidemiological features and prognosis of mesotheliomas with environmental asbestos exposure. Respir Med. 2001; 95:588-93.

40. Tsou JA, Galler JS, Wali A, Ye W, Siegmund KD, Groshen S, Laird PW, Turla S, Koss MN, Pass HI, Laird-Offringa IA. DNA methylation profile of 28 potential marker loci in malignant mesothelioma. Lung Cancer. 2007; 58:220-30.

41. Surowiak P, Kaplenko I, Spaczynski M, Zabel M. The expression of metallothionein (MT) and proliferation intensity in ovarian cancers treated with cisplatin and paclitaxel. Folia Morphol (Warsz). 2003; 62:493-5.

42. Surowiak P, Materna V, Maciejczyk A, Pudelko M, Markwitz E, Spaczynski M, Dietel M, Zabel M, Lage H. Nuclear metallothionein expression correlates with cisplatin resistance of ovarian cancer cells and poor clinical outcome. Virchows Arch. 2007; 450:279-85.

43. Theocharis SE, Margeli AP, Klijanienko JT, Kouraklis GP. Metallothionein expression in human neoplasia. Histopathology. 2004; 45:103-18.

44. Guo Y, Xiao P, Lei S, Deng F, Xiao GG, Liu Y, Chen X, Li L, Wu S, Chen Y, Jiang H, Tan L, Xie J, et al. How is mRNA expression predictive for protein expression? A correlation study on human circulating monocytes. Acta Biochim Biophys Sin (Shanghai). 2008; 40:426-36.

45. Chen G, Gharib TG, Huang CC, Taylor JM, Misek DE, Kardia SL, Giordano TJ, Iannettoni MD, Orringer MB, Hanash SM, Beer DG. Discordant protein and mRNA expression in lung adenocarcinomas. Mol Cell Proteomics. 2002; 1:304-13.

46. Pascal LE, True LD, Campbell DS, Deutsch EW, Risk M, Coleman IM, Eichner LJ, Nelson PS, Liu AY. Correlation of mRNA and protein levels: cell type-specific gene expression of cluster designation antigens in the prostate. BMC Genomics. 2008; 9:246.

47. Siu LL, Banerjee D, Khurana RJ, Pan X, Pflueger R, Tannock IF, Moore MJ. The prognostic role of $\mathrm{p} 53$, metallothionein, P-glycoprotein, and MIB-1 in muscleinvasive urothelial transitional cell carcinoma. Clin Cancer Res. 1998; 4:559-65.

48. Monden N, Abe S, Hishikawa Y, Yoshimura H, Kinugasa S, Dhar DK, Tachibana M, Nagasue N. The role of P-glycoprotein in human gastric cancer xenografts in response to chemotherapy. Int J Surg Investig. 1999; 1:3-10.

49. Hishikawa Y, Koji T, Dhar DK, Kinugasa S, Yamaguchi M, Nagasue N. Metallothionein expression correlates with metastatic and proliferative potential in squamous cell carcinoma of the oesophagus. Br J Cancer. 1999; 81:712-20. 
50. Eid H, Geczi L, Magori A, Bodrogi I, Institoris E, Bak M. Drug resistance and sensitivity of germ cell testicular tumors: evaluation of clinical relevance of MDR1/Pgp, p53, and metallothionein (MT) proteins. Anticancer Res. 1998; 18:3059-64.

51. Meijer C, Timmer A, De Vries EG, Groten JP, Knol A, Zwart N, Dam WA, Sleijfer DT, Mulder NH. Role of metallothionein in cisplatin sensitivity of germ-cell tumours. Int J Cancer. 2000; 85:777-81.

52. Endo T, Yoshikawa M, Ebara M, Kato K, Sunaga M, Fukuda H, Hayasaka A, Kondo F, Sugiura N, Saisho H. Immunohistochemical metallothionein expression in hepatocellular carcinoma: relation to tumor progression and chemoresistance to platinum agents. J Gastroenterol. 2004; 39:1196-201.

53. Klaassen CD, Liu J, Choudhuri S. Metallothionein: an intracellular protein to protect against cadmium toxicity. Ann Rev Pharmacol Toxicol. 1999; 39:267-94.

54. Cherian MG, Jayasurya A, Bay BH. Metallothioneins in human tumors and potential roles in carcinogenesis. Mutat Res. 2003; 533:201-9.

55. Hagrman D, Goodisman J, Dabrowiak JC, Souid AK. Kinetic study on the reaction of cisplatin with metallothionein. Drug Metab Dispos. 2003; 31:916-23.

56. Vasak M. Advances in metallothionein structure and functions. J Trace Elem Med Biol. 2005; 19:13-7.

57. Karotki AV, Vasak M. Reaction of human metallothionein-3 with cisplatin and transplatin. J Biol Inorg Chem. 2009; $14: 1129-38$

58. Knipp M, Karotki AV, Chesnov S, Natile G, Sadler PJ, Brabec V, Vašák M. Reaction of Zn7metallothionein with cis- and trans-[Pt(N-donor)2Cl2] anticancer complexes: trans-Pt(II) complexes retain their N-donor ligands. J Med Chem. 2007; 50:4075-86.

59. Knipp M. Metallothioneins and platinum(II) anti-tumor compounds. Curr Med Chem. 2009; 16:522-37.

60. Butler JS, Loh SN. Structure, function, and aggregation of the zinc-free form of the p53 DNA binding domain. Biochemistry. 2003; 42:2396-403.

61. Formigari A, Irato P, Santon A. Zinc, antioxidant systems and metallothionein in metal mediated-apoptosis: biochemical and cytochemical aspects. Comp Biochem Physiol C Toxicol Pharmacol. 2007; 146:443-59.

62. Walter RF, Vollbrecht C, Werner R, Wohlschlaeger J, Christoph DC, Schmid KW, Mairinger FD. microRNAs are differentially regulated between MDM2-positive and negative malignant pleural mesothelioma. Oncotarget. 2016; 7:18713-21. https://doi.org/10.18632/oncotarget.7666.

63. Walter RF, Mairinger FD, Ting S, Vollbrecht C, Mairinger T, Theegarten D, Christoph DC, Schmid KW, Wohlschlaeger J. MDM2 is an important prognostic and predictive factor for platin-pemetrexed therapy in malignant pleural mesotheliomas and deregulation of P14/ARF (encoded by CDKN2A) seems to contribute to an MDM2-driven inactivation of P53. Br J Cancer. 2015; 112:883-90.

64. Mairinger FD, Walter RF, Ting S, Vollbrecht C, Kollmeier J, Griff S, Hager T, Mairinger T, Christoph DC, Theegarten D, Schmid KW, Wohlschlaeger J. Mdm2 protein expression is strongly associated with survival in malignant pleural mesothelioma. Future Oncol. 2014; 10:995-1005.

65. Kocdor H, Ates H, Aydin S, Cehreli R, Soyarat F, Kemanli P, Harmanci D, Cengiz H, Kocdor MA. Zinc supplementation induces apoptosis and enhances antitumor efficacy of docetaxel in non-small-cell lung cancer. Drug Des Devel Ther. 2015; 9:3899-909.

66. Alscher DM, Biegger D, Kuhlmann U, Fritz P. Induction of metallothionein in mesothelial cells by zinc. Artif Organs. 2007; 31:488-91.

67. Travis WD, World Health Organization, International Agency for Research on Cancer, International Association for the Study of Lung Cancer, International Academy of Pathology. Pathology and genetics of tumours of the lung, pleura, thymus and heart. Lyon Oxford: IARC Press Oxford University Press (distributor); 2004. 344 p. p.

68. Sobin LH, Gospodarowicz MK, Wittekind C; International Union against Cancer. TNM classification of malignant tumours. 7th ed. Chichester, West Sussex, UK ; Hoboken, NJ: Wiley-Blackwell; 2010. xx, 309 p. p.

69. Byrne MJ, Nowak AK. Modified RECIST criteria for assessment of response in malignant pleural mesothelioma. Ann Oncol. 2004; 15:257-60.

70. Mairinger FD, Vollbrecht C, Flom E, Christoph DC, Schmid KW, Kollmeier J, Popper HH, Mairinger T, Walter RFH. Folic acid phenotype (FAP) is a superior biomarker predicting response to pemetrexed-based chemotherapy in malignant pleural mesothelioma. Oncotarget. 2017; 8:37502-10.https://doi.org/10.18632/oncotarget.16398.

71. Gamble LD, Kees UR, Tweddle DA, Lunec J. MYCN sensitizes neuroblastoma to the MDM2-p53 antagonists Nutlin-3 and MI-63. Oncogene. 2012; 31:752-63.

72. Herce HD, Deng W, Helma J, Leonhardt H, Cardoso MC. Visualization and targeted disruption of protein interactions in living cells. Nat Commun. 2013; 4:2660.

73. Vandermeers F, Hubert P, Delvenne P, Mascaux C, Grigoriu B, Burny A, Scherpereel A, Willems L. Valproate, in combination with pemetrexed and cisplatin, provides additional efficacy to the treatment of malignant mesothelioma. Clin Cancer Res. 2009; 15:2818-28.

74. Rytelewski M, Maleki Vareki S, Mangala LS, Romanow L, Jiang D, Pradeep S, Rodriguez-Aguayo C, Lopez-Berestein G, Figueredo R, Ferguson PJ, Vincent M, Sood AK, Koropatnick JD. Reciprocal positive selection for weakness - preventing olaparib resistance by inhibiting BRCA2. Oncotarget. 2016; 7:20825-39. https://doi.org/10.18632/ oncotarget.7883.

75. O'Kane SL, Eagle GL, Greenman J, Lind MJ, Cawkwell L. COX-2 specific inhibitors enhance the cytotoxic effects of 
pemetrexed in mesothelioma cell lines. Lung Cancer. 2010; 67:160-5.

76. Zucali PA, Giovannetti E, Destro A, Mencoboni M, Ceresoli GL, Gianoncelli L, Lorenzi E, De Vincenzo F, Simonelli M, Perrino M, Bruzzone A, Thunnissen E, Tunesi G. Thymidylate synthase and excision repair crosscomplementing group- 1 as predictors of responsiveness in mesothelioma patients treated with pemetrexed/carboplatin. Clin Cancer Res. 2011; 17:2581-90.

77. Goulding H, Jasani B, Pereira H, Reid A, Galea M, Bell JA, Elston CW, Robertson JF, Blamey RW, Nicholson RA. Metallothionein expression in human breast cancer. Br J Cancer. 1995; 72:968-72.
78. Schmid KW, Ellis IO, Gee JM, Darke BM, Lees WE, Kay J, Cryer A, Stark JM, Hittmair A, Ofner D. Presence and possible significance of immunocytochemically demonstrable metallothionein over-expression in primary invasive ductal carcinoma of the breast. Virchows Arch A Pathol Anat Histopathol. 1993; 422:153-9.

79. Waggott D, Chu K, Yin S, Wouters BG, Liu FF, Boutros PC. NanoStringNorm: an extensible R package for the pre-processing of NanoString mRNA and miRNA data. Bioinformatics. 2012; 28:1546-8. 